
About IJMA [last updated July, $\left.1^{\text {st }}, 2021\right]$

$\checkmark$ International Journal of Medical Arts is the Official Journal of the Damietta Faculty of Medicine, AlAzhar University, Egypt

$\checkmark$ It is an International, Open Access, Double-blind, Peer-reviewed Journal

$\checkmark$ Published four times a year

$\checkmark$ The First Issue was published in July 2019

$\checkmark$ Published under the following license: Creative Commons Attribution-ShareAlike 4.0 International Public License (CC BY-SA 4.0). It had updated from the Creative Commons license [CC BY] in volume 2, Issue 4, October 2020 About IJMA

$\checkmark$ The Egyptian Knowledge Bank hosts the web site of IJMA

$\checkmark$ The Egyptian Knowledge Bank supports IJMA

$\checkmark$ IJMA follows the regulations of the International Committee of Medical Journal Editors

$\checkmark$ IJMA is indexed in the "Directory of Open Access Journals" [15 January 2021].

$\checkmark$ IJMA is indexed in JGate [29-6-2021]

$\checkmark$ IJMA is a member of the International Society of Managing and Technical Editors

$\checkmark$ Listed in "Index Copernicus", "Publons", "Academic resource index [ResearchBib]", "Electronics journal library", "Eurasian Scientific Journal Index", and "Citefactor"

$\checkmark$ IJMA introduced to the search engine [BASE] through DOAJ
Click image to reach the page

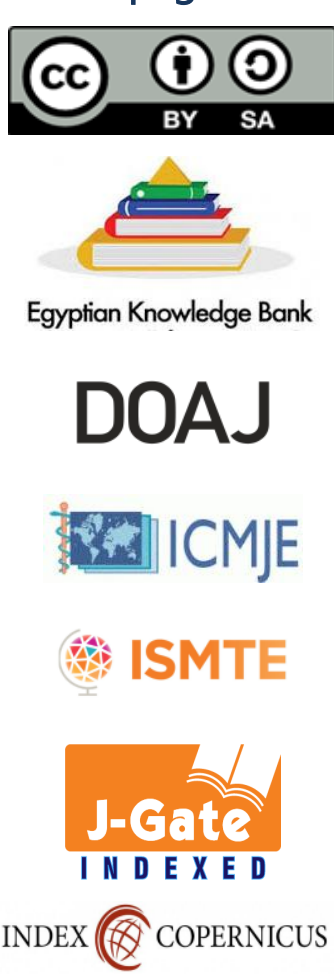

publons

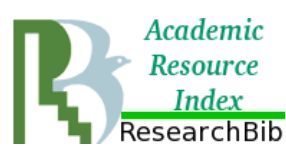

\section{EZ3 \\ .}

ESJII

CiteFactor

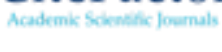

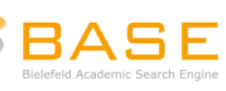




Available online at Journal Website
https://ijma.journals.ekb.eg/
Main subject [Pediatrics]

Original Article

\title{
Ventricular Function and Pulmonary Artery Pressure in Children with Mild and Moderate Bronchial Asthma
}

\author{
Tarek Kotb Alsayad [1]; Saad Ahmed Mohamed [2] \\ 1 Department of Pediatrics, Pediatric Cardiology Division, Faculty of Medicine, Al-Azhar University, Egypt \\ 2 Department of Pediatrics, Damietta Faculty of Medicine, Al-Azhar University, Egypt \\ Corresponding author: Tarek Kotb Alsayad \\ Email: elsayadtarek@gmail.com
}

Submission date: May 21, 2021; Acceptance date: August 05, 2021

DOI: $10.21608 /$ ijma.2021.187835

DOAJ

Background: Bronchial asthma is a chronic airway disease. Cardiac affection in children with bronchial asthma was reported mainly in cases with severe asthma and during acute exacerbations.

Aim of the Work: To study cardiac affection in children with mild and moderate bronchial asthma using conventional and tissue Doppler imaging [TDI] echocardiography.

Patients and Methods: This was a prospective case control study. Study involved 160 children aged 6-14 years old who were following in outpatient pediatric clinic, Al-Hussein hospital, Al-Azhar University, Cairo, Egypt, during the period from January 4, 2016, till February 15, 2017. All children underwent peak expiratory flow rate [PEFR] assessment. Echocardiography was done for all to assess systolic and diastolic functions of right ventricle [RV] and left ventricle [LV] using conventional and tissue Doppler imaging [TDI] echocardiography.

Results: TDI parameters showed evidence of RV diastolic dysfunction in patients with moderate asthma in the form of significantly lower tricuspid valve [TV] e' [12.1 $\pm 2.7 \mathrm{~cm} / \mathrm{s}]$, lower TV e'/a' ratio [1.28 \pm 0.18$]$, prolonged RV isovolumetric relaxation time [IVRT] [71.8 $\pm 2.4 \mathrm{~ms}$ ], and higher RV myocardial performance index [0.49 \pm 0.04$]$ compared to control group. Also, patients with mild asthma had impaired RV diastolic function in the form of significantly lower TV e'/a' [1.51 \pm 0.13 ] and longer RV IVRT [65 $\pm 2.9 \mathrm{~ms}$ ] compared to control group. Pulmonary artery pressure was significantly elevated in moderate asthma group [18.4 $\pm 9.2 \mathrm{mmHg}]$. RV IVRT was the only parameter showing a significant negative correlation to PEFR

Conclusion: Pediatric patients with mild and moderate bronchial asthma may have RV diastolic dysfunction. TDI is a good screening tool to detect early changes in cardiac function in such patients. RV IVRT measured by TDI is a sensitive tool to detect early diastolic impairment.

Keywords: Bronchial Asthma; Children; Ventricular Function; Tissue Doppler Imaging; Pulmonary Artery Pressure.

This is an open-access article registered under the Creative Commons, ShareAlike 4.0 International license [CC BY-SA 4.0] [https://creativecommons.org/licenses/by-sa/4.0/legalcode.

Citation: Alsayad TK, Mohamed SA. Ventricular Function and Pulmonary Artery Pressure in Children with Mild and Moderate Bronchial Asthma. IJMA 2021; 3[3]: JulySeptember: 1754-1760. [DOI: 10.21608/ijma.2021.187835].

Main subject and any subcategories have been classified according to the research topic 


\section{INTRODUCTION}

Bronchial asthma is a chronic inflammatory disease involving the lung airways leading to recurrent airways obstruction and hyper-responsiveness. Chronic nature of bronchial asthma may lead to a gradual loss of lung function and change of pulmonary circulation that occur due to structural changes and remodeling of airways and pulmonary vessels ${ }^{[1]}$.

Several mechanisms can explain the impact of chronic lung diseases on the heart including recurrent hypoxemia, the release of inflammatory mediators, changes in the pulmonary vasculature, and increased intra-thoracic pressure. These mechanisms directly affect the right ventricle via increasing the pulmonary artery pressure. Left ventricular dysfunction was also reported with chronic lung diseases secondary to changes in the interaction between the right and left ventricles and changes in the ventricular preload and afterload [2].

Echocardiography is the primary noninvasive tool to assess ventricular function. Using conventional echocardiography, it is easy to assess left ventricular function. On the other hand, it is more difficult to assess RV function using the same modality because of the very close relation of the right ventricle to the sternum and its complex morphology and heavy trabeculations on the endocardium ${ }^{[3]}$

Tissue Doppler imaging [TDI] echocardiography emerged as a unique method to assess regional ventricular systolic and diastolic velocities and various time intervals during the cardiac cycle. Moreover, it is more sensitive and can detect abnormalities earlier than conventional echocardiography ${ }^{[4]}$.

Although previous studies showed variable cardiac affections in asthmatic patients, the results were not universally homogenous. Many previous studies assessed cardiac function in asthmatic patients without discrimination between them according to asthma severity. Moreover, we are not sure when these effects take place during the course of bronchial asthma particularly in children, and if those with milder forms of asthma are having any cardiac function abnormality.

\section{THE AIM OF THE WORK}

Our study aimed to detect any changes in the systolic or diastolic function of both ventricles using conventional echocardiography and TDI in children having mild or moderate bronchial asthma during remission and to assess pulmonary artery pressure in these patients.
PATIENTS AND METHODS

This was a prospective case control study conducted on 160 children aged 6-14 years old who were following in outpatient pediatric clinic, Al-Hussein hospital, Al-Azhar University, Cairo, Egypt, during the period from January 4, 2016, till February 15, 2017.

Our study population was composed of three groups: the first group involved 40 children who were diagnosed to have mild bronchial asthma and the second group involved 40 children with moderate bronchial asthma according to guidelines of the Global Strategy for Asthma Management and Prevention [5].

All asthmatic patients were assessed during remission. None of them was having acute exacerbation or history of acute upper or lower respiratory infection during the last month. The third group involved 80 normal children as a control group. Control children were recruited from the outpatient pediatric clinic who came for other minor complaints.

Exclusion criteria were children diagnosed as severe bronchial asthma or having any comorbidity that compromises respiratory or cardiovascular systems including cardiac diseases, respiratory infections, chronic lung diseases, acute asthmatic attacks during the last 30 days, morbid obesity, gastroesophageal reflux, or chest deformity.

We also excluded children with suboptimal echocardiographic views. All patients were subjected to complete history taking and thorough physical examination, including taking anthropometric measurements and vital signs.

The peak expiratory flow rate [PEFR] was measured for each patient using Mini Wright peak flow meter [by Climent Clark International, New York, USA]. The best reading from three forced expirations was taken. A chest $\mathrm{X}$-ray was done to exclude underlying lung disease.

Echocardiography was performed using GE vivid 3 echocardiography machine [General Electric Medical Systems, Milwaukee, USA] equipped with $3 \mathrm{MHz}$ and 5 $\mathrm{MHz}$ transducers. Parameters recorded according to guidelines of the American Society of Echocardiography using two-dimensional recording [2D echocardiography], pulsed wave Doppler [PW], continuous wave Doppler [CW], TDI and M-mode ${ }^{[6,7] \text {. }}$

Ventricular dimensions were assessed by M-mode: right ventricular diameter in diastole [RVDd], thickness of $\mathrm{RV}$ free wall [RVWT], left ventricular diameter in diastole 
[LVDd] and left ventricular posterior wall thickness [LVPWT].

Right ventricle $[R V]$ systolic function was evaluated by measuring fractional area change [RV FAC] by $2 \mathrm{D}$ echocardiography, Tricuspid annular plane systolic excursion [TAPSE] by M-mode and lateral tricuspid annulus systolic velocity [S'] by TDI.

LV systolic function was determined by measuring ejection fraction [EF] using M-mode and lateral mitral annulus systolic velocity [S'] using TDI.

The diastolic function of both ventricles was assessed using conventional echocardiography and TDI. Early [E] and late $[A]$ diastolic inflow velocities of the corresponding atrioventricular valve were measured by conventional pulsed-wave Doppler and then E/A ratio for each was calculated.

TDI was used to measure lateral tricuspid annulus and lateral mitral annulus peak early diastolic velocity [e'] and peak late diastolic velocity [a'], isovolumetric relaxation time [IVRT], isovolumetric contraction time [IVCT] and ejection time [ET].

The ratio e'la' at tricuspid and mitral valves was calculated for each patient. Myocardial performance index [MPI] for each ventricle was calculated according to the formula: MPI = [ICT + IRT]/ET. MPI assesses the combined systolic and diastolic function.

Evaluation of pulmonary artery pressure [PAP] was done using CW Doppler to measure peak tricuspid valve regurgitation velocity [TRV]. PAP was calculated according to the formula: $\mathrm{PAP}=\mathrm{TRV}{ }^{2}+$ right atrial pressure. Right atrial pressure was assumed to be $5 \mathrm{mmHg}$ in all included children. Pulmonary acceleration time [AT] and ejection time [ET] were also measured and the ratio AT/ET was determined.

\section{Ethical considerations}

Ethical approval was obtained from the local health committee. For all children involved in our study, we obtained informed written consent from parents. Privacy and confidentiality were maintained throughout the study process using a unique code number for each patient.

\section{Statistical analysis of data}

Statistical package for social sciences was used for data analysis. We used package version 25.0 [IBM SPSS. Armonk, NY: IBM Corporation, USA]. For descriptive statistics: the mean \pm SD was used for quantitative variables while the number and percentage were used for qualitative variables. For analytic statistics: Chi-square test was used to assess the differences in frequency of qualitative variables while One-Way ANOVA test was applied to assess the differences in means of quantitative variables between more than two groups. Post Hoc test with Bonferoni adjustment was used to determine which differences between groups were significant. Pearson's correlation coefficient was used to correlate various quantitative variables. The statistical methods were verified, assuming a significant level of $p<0.05$ and a highly significant level of $p<0.001$.

\section{RESULTS}

There was no significant difference between the three groups regarding age, sex, anthropometric measurements, or vital signs. PEFR was significantly less in both mild asthma group and moderate asthma group compared to the control group [table 1].

Table [2] shows different echocardiographic RV parameters for the three groups. There was no significant difference in RV systolic function parameters: FAC, TAPSE, and lateral TV annular Systolic velocity [S']. There was no significant difference between the three groups regarding RV diastolic parameters measured by conventional Doppler: $E$ and $A$ and the $E / A$ ratio. On comparing moderate asthma group to control group four RV parameters measured by TDI showed significant difference: e', e'/a', IVRT, and MPI. Both e' and e'/a' were lower in moderate asthma group, while IVRT and MPI were higher. On the other hand, on comparing mild asthma group to control group only e'/a' and IVRT were significantly different from the control group. RV dimensions showed no significant difference in all groups.

All systolic and diastolic LV parameters showed no significant difference between the three groups. Also, LV dimensions were similar in the three groups [Table 3].

Pulmonary artery pressure showed significant increase in moderate asthma group compared to control with significant decrease in pulmonary AT and significant decrease in AT/ET ratio. On the other hand, these parameters were comparable between mild asthma and control groups [Table 4].

We tried to find a relation between RV diastolic parameters measured by TDI and PEFR. We selected these parameters that came significantly different in asthmatic children. IVRT was the only parameter that had a significant negative correlation to PEFR [Table 5]. 
Table [1]: Demographic, anthropometric and clinical characteristics

\begin{tabular}{|c|c|c|c|c|}
\hline \multirow[b]{2}{*}{ Variable } & \multicolumn{2}{|c|}{ Asthmatic group } & \multirow[b]{2}{*}{ Control group $(n=80)$} & \multirow[b]{2}{*}{ P-value } \\
\hline & Mild $(n=40)$ & Moderate $(n=40)$ & & \\
\hline Age [years] & $11.4 \pm 3.0$ & $12.7 \pm 2.8$ & $12.8 \pm 2.8$ & 0.134 \\
\hline Sex $n[\%]$ & & & & \\
\hline Male & $21[52.0]$ & $22[55.0]$ & $40[50.0]$ & 0.895 \\
\hline Female & $19[48.0]$ & $18[45.0]$ & $40[50.0]$ & \\
\hline Weight [kg] & $41 \pm 5.7$ & $41 \pm 4.6$ & $40 \pm 6.2$ & 0.708 \\
\hline Height [cm] & $135 \pm 11$ & $132 \pm 12$ & $134 \pm 14$ & 0.694 \\
\hline Heart rate [bpm] & $105.7 \pm 16.2$ & $101 \pm 10.9$ & $102.6 \pm 15.4$ & 0.508 \\
\hline Systolic blood pressure $(\mathrm{mmHg})$ & $106.8 \pm 7.3$ & $108 \pm 6.9$ & $109.4 \pm 5.8$ & 0.293 \\
\hline Diastolic blood Pressure $(\mathrm{mmHg})$ & $64.2 \pm 5.7$ & $66.2 \pm 4.7$ & $62.7 \pm 6.4$ & 0.065 \\
\hline PEFR [L/min] & $251.8 \pm 17.2$ & $239.4 \pm 17.8$ & $266 \pm 15.5$ & $<0.001^{*} ¥$ \\
\hline
\end{tabular}

Abbreviations: PEFR, peak expiratory flow rate. Values present as mean \pm SD were analyzed by One-way ANOVA test. Values present as number and \% were analyzed by

Chi-square test. *: Significant, between moderate asthma group and the control group. ¥: Significant, between mild asthma group and the control group.

Table [2]: Right ventricular functions and dimensions

\begin{tabular}{|c|c|c|c|c|c|}
\hline \multicolumn{2}{|r|}{ Variable } & \multicolumn{2}{|c|}{ Asthmatic group } & \multirow{2}{*}{$\begin{array}{c}\text { Control group } \\
(n=80)\end{array}$} & \multirow{2}{*}{ P-value } \\
\hline & & Mild ( $n=40)$ & Moderate & & \\
\hline \multirow[t]{3}{*}{ RV Systolic function } & FAC [\%] & $38.9 \pm 3.1$ & $37.8 \pm 2.6$ & $39.2 \pm 2.3$ & 0.110 \\
\hline & TAPSE $[\mathrm{cm}]$ & $1.8 \pm 0.19$ & $1.8 \pm 0.23$ & $1.9 \pm 0.19$ & 0.071 \\
\hline & Lateral TV annular Systolic velocity S' [cm/s] & $10.9 \pm 0.91$ & $10.8 \pm 0.85$ & $11.2 \pm 0.69$ & 0.115 \\
\hline \multirow[t]{9}{*}{ RV Diastolic function } & TV E velocity [cm/s] & $84.1 \pm 9.5$ & $83.8 \pm 8.6$ & $86.6 \pm 8.8$ & 0.379 \\
\hline & TV A velocity [cm/s] & $57.1 \pm 4.9$ & $56.2 \pm 8.2$ & $55.8 \pm 9.1$ & 0.811 \\
\hline & TV E/A ratio & $1.5 \pm 0.45$ & $1.5 \pm 0.37$ & $1.6 \pm 0.49$ & 0.578 \\
\hline & Lateral TV e' velocity $[\mathrm{cm} / \mathrm{s}]$ & $13.2 \pm 2.8$ & $12.1 \pm 2.7$ & $14.8 \pm 3.2$ & $0.002^{*}$ \\
\hline & Lateral TV a' velocity $[\mathrm{cm} / \mathrm{s}]$ & $8.7 \pm 1.9$ & $8.4 \pm 1.4$ & $8.6 \pm 2.1$ & 0.746 \\
\hline & TV e'/a' ratio & $1.51 \pm 0.13$ & $1.28 \pm 0.18$ & $1.77 \pm 0.51$ & $<0.001^{*} ¥$ \\
\hline & IVRT [ms] & $65 \pm 2.9$ & $71.8 \pm 2.4$ & $60.1 \pm 2.8$ & $<0.001^{*} ¥$ \\
\hline & IVCT [ms] & $65 \pm 5.5$ & $66.1 \pm 3.8$ & $63.1 \pm 5.9$ & 0.076 \\
\hline & MPI & $0.42 \pm 0.07$ & $0.49 \pm 0.04$ & $0.40 \pm 0.02$ & $<0.001^{*}$ \\
\hline \multirow[t]{2}{*}{ RV dimensions } & RVDd [cm] & $0.9 \pm 0.2$ & $0.9 \pm 0.3$ & $0.8 \pm 0.2$ & 0.133 \\
\hline & RVWT [cm] & $0.48 \pm 0.13$ & $0.49 \pm 0.03$ & $0.48 \pm 0.06$ & 0.293 \\
\hline
\end{tabular}

Abbreviations: FAC, fractional area change; IVCT, isovolumetric contraction time; IVRT, isovolumetric; relaxation time; MPI, myocardial performance index; RVDd, right ventricular diameter in diastole; RVWT, right ventricular wall thickness; TAPSE, Tricuspid annular plane systolic excursion; TV, Tricuspid valve. Values present as mean \pm SD were analyzed by One-way ANOVA test. *: Significant, between moderate asthma group and the control group. ¥: Significant, between mild asthma group and the control group.

Table [3]: Left ventricular functions and dimensions

\begin{tabular}{|c|c|c|c|c|c|}
\hline \multirow{2}{*}{\multicolumn{2}{|c|}{ Variable }} & \multicolumn{2}{|c|}{ Asthmatic group } & \multirow[b]{2}{*}{ Control group $(n=80)$} & \multirow[b]{2}{*}{ P-value } \\
\hline & & Mild $(n=40)$ & Moderate $(n=40)$ & & \\
\hline \multirow[t]{2}{*}{ LV systolic function } & EF [\%] & $63 \pm 5.8$ & $67 \pm 7.7$ & $65 \pm 5.9$ & 0.094 \\
\hline & Lateral MV systolic velocity S' [cm/s] & $12.0 \pm 2.1$ & $11.8 \pm 1.6$ & $12.2 \pm 1.7$ & 0.101 \\
\hline \multirow{9}{*}{ LV diastolic function } & MV E velocity [cm/s] & $97.3 \pm 5.6$ & $98.6 \pm 11.2$ & $100.2 \pm 9.6$ & 0.457 \\
\hline & MV A velocity [cm/s] & $71.9 \pm 8.7$ & $71.4 \pm 8.5$ & $73.1 \pm 9.2$ & 0.730 \\
\hline & MV E/A ratio [cm/s] & $1.3 \pm 0.21$ & $1.4 \pm 0.18$ & $1.4 \pm 0.24$ & 0.152 \\
\hline & Lateral MV e' [cm/s] & $12.9 \pm 1.4$ & $12.4 \pm 1.3$ & $13.1 \pm 1.6$ & 0.176 \\
\hline & Lateral MV a' & $6.5 \pm 1.5$ & $6.7 \pm 1.7$ & $6.4 \pm 1.9$ & 0.684 \\
\hline & MV e'/a' & $2.05 \pm 0.35$ & $1.93 \pm 0.39$ & $2.1 \pm 0.4$ & 0.219 \\
\hline & IVRT [ms] & $63.8 \pm 3.7$ & $64.2 \pm 2.4$ & $62.7 \pm 6.2$ & 0.420 \\
\hline & IVCT [ms] & $60.8 \pm 5.1$ & $60.4 \pm 4.8$ & $61.7 \pm 5.4$ & 0.583 \\
\hline & MPI & $0.41 \pm 0.06$ & $0.41 \pm 0.09$ & $0.39 \pm 0.1$ & 0.564 \\
\hline \multirow[t]{2}{*}{ LV dimensions } & LVDd [cm] & $3.9 \pm 0.5$ & $3.9 \pm 0.3$ & $4.1 \pm 0.6$ & 0.181 \\
\hline & LVPWT [cm] & $0.51 \pm 0.03$ & $0.5 \pm 0.02$ & $0.5 \pm 0.05$ & 0.546 \\
\hline
\end{tabular}

Abbreviations: EF, ejection fraction; IVCT, isovolumetric contraction time; IVRT, isovolumetric relaxation time; LVDd, left ventricular diameter in diastole; LVPWT, left ventricular posterior wall thickness; MPI, myocardial performance index; MV, Mitral valve. Values present as mean \pm SD were analyzed by One-way ANOVA test. 
Table [4]: Assessment of pulmonary artery pressure

\begin{tabular}{|l|c|c|c|c|}
\hline \multirow{2}{*}{ Variable } & \multicolumn{2}{|c|}{ Asthmatic group } & \multirow{2}{*}{ Control group $(\mathrm{n}=\mathbf{8 0})$} & \multirow{2}{*}{ P-value } \\
\cline { 2 - 3 } & Mild $(\mathbf{n = 4 0 )}$ & Moderate $(\mathbf{n = 4 0 )}$ & $13 \pm 8.4$ & $0.040^{*}$ \\
\hline PAP [mmHg] & $14 \pm 7.4$ & $18.4 \pm 9.2$ & $121 \pm 12.0$ & $0.023^{*}$ \\
\hline AT & $124 \pm 13.2$ & $114 \pm 14.4$ & $0.48 \pm 0.15$ & $0.039^{*}$ \\
\hline AT/ET & $0.42 \pm 0.15$ & $0.39 \pm 0.12$ & & \\
\hline
\end{tabular}

Abbreviations: AT, acceleration time; ET, ejection time; PAP, pulmonary artery pressure. Values presented as mean \pm SD were analyzed by One-way ANOVA test. Significant, between moderate asthma group and the control group.

Table [5]: Correlation between echocardiographic parameters and asthma severity

\begin{tabular}{|l|c|c|}
\hline \multirow{2}{*}{ Parameter } & \multicolumn{2}{c|}{ PEFR } \\
\cline { 2 - 3 } & \multicolumn{1}{c|}{$\boldsymbol{P}$} \\
\hline TV e' & 0.005 & 0.973 \\
\hline TV e'la' & 0.205 & 0.152 \\
\hline RV IVRT & -0.458 & $0.001^{*}$ \\
\hline RV MPI & -0.115 & 0.238 \\
\hline
\end{tabular}

Abbreviations: MPI, myocardial performance index; IVRT, isovolumetric relaxation time. *: Significant.

\section{DISCUSSION}

We aimed to assess changes in cardiac function may occur in children with mild and moderate spectrum of bronchial asthma during remission. In our study, there was no statistically significant difference between asthmatic children groups and the control group regarding weight, heart rate, systolic and diastolic blood pressure. In addition, there was no significant difference between the three groups regarding $\mathrm{RV}$ or $\mathrm{LV}$ dimensions.

Although similar findings were found by other studies [8,9], earlier reports revealed variable results on assessing cardiac dimensions in asthmatic children. Some studies described RV hypertrophy in asthmatic patients [10-12]. Another study described RV dilatation rather than hypertrophy [13]. These variations can be explained by the difference in study populations and the fact that we did not include patients with severe asthma in our study.

We did not find any significant difference between the three groups regarding RV systolic function parameters [FAC, TAPSE, and Lateral TV annular systolic velocity]. Preserved RV systolic function in asthmatic children was previously reported in the literature ${ }^{[8,14,15]}$.

Other studies found evidence of RV systolic dysfunction in asthmatic patients in the form of lower TAPSE or lower lateral TV systolic velocity than the control group [9,11]. Discordance between our results and previous studies can be because we excluded patients with severe asthma, relatively younger age of our patients.

RV diastolic function parameters obtained by conventional Doppler at TV $[E, A$, and $E / A]$ were similar in the three groups of our study. Concordant results were obtained by previous studies [9,11]. Some studies showed evidence of RV diastolic dysfunction using conventional
Doppler in the form of lower TV E velocity or lower TV E/A ratio in asthmatic children but they included patients with severe asthma in their study population $[8,15]$.

We further assessed RV diastolic function using TDI. We found a significant difference between moderate asthma group and control group in TV e', TV e'/a', IVRT, and MPI indicating that those with moderate asthma have impaired RV diastolic function. This was in agreement with previous studies that assessed RV diastolic function in asthmatic children ${ }^{[0-11,16]}$.

In our study, we assessed patients with mild asthma as a separate group. RV e'la' and IVRT were the only RV parameters showed significant difference suggesting milder diastolic dysfunction in this group. Only very few studies investigated cardiac affection in patients with mild asthma as a separate group. Zeybek et al. found that patients with mild asthma are different from the control group regarding both RV e' and IVRT [15].

We did not find any significant difference between all groups regarding parameters of LV diastolic functions. These findings were in line with previous studies [10,13].

LV diastolic dysfunction was reported in patients with chronic obstructive lung diseases and it was more evident in those having severe pulmonary hypertension [17-19]. Some studies found evidence of LV diastolic dysfunction mainly in patients with severe asthma ${ }^{[8,9]}$.

Zeybek et al. noticed LV diastolic dysfunction in bronchial asthma groups when measured by TDI not by conventional echocardiography [15]. Elmasry et al. showed that asthmatic patients had LV diastolic dysfunction during acute exacerbation evidenced by lower E/A ratio and longer IVRT and these changes were normalized after clinical improvement ${ }^{[20]}$. 
LV systolic function can be affected in patients with severe asthma secondary to RV affection due to interdependence between both ventricles ${ }^{[15,21,22]}$.

Hirono et al. found that bronchial asthma patients who are using beta agonists for a long period had lower LV systolic function [23]. Tuleta et al. found reduction in the LV longitudinal strain in patients with severe asthma [24]. This explains why there was normal LV systolic function in our asthmatic groups who had milder spectrum of asthma and younger age.

We found significant increase in pulmonary artery pressure in moderate asthma group. This was in line with previous studies who found that asthmatic patients had higher pulmonary artery pressure compared to controls [25,26]. Pulmonary artery pressure in mild asthma group was comparable with control group. While we can explain diastolic dysfunction in moderate asthma group by pulmonary hypertension, diastolic dysfunction in mild asthma group may be due to cardiac stress during asthma exacerbations resulting from acute increase in pulmonary artery pressure and the concomitant inflammatory response. Released cytokines in such situation was reported as a direct cause of myocardial impairment [27,28].

Our study showed that pediatric patients with moderate bronchial asthma during remission have evidence of RV diastolic dysfunction and patients with mild bronchial asthma during remission have milder diastolic dysfunction in the absence of significant increase in pulmonary artery pressure. TDI is a sensitive tool to detect RV diastolic dysfunction. RV IVRT and RV e'/a' measured by TDI can be used as a screening tool to pick up early RV diastolic dysfunction even in patients with mild asthma. RV IVRT is correlated to pulmonary function so it can be used as a predictor of asthma severity. Early screening and follow up for cardiac function in asthmatic patients should be considered. More effort is needed to understand the pathophysiology of cardiac affection in asthmatic patients.

Limitations to our study included a relatively small number of the study population. Also, we assessed pulmonary function using PEFR as a single parameter. However, PEFR was shown to be a reliable alternative to forced expiratory volume in one second as a primary lung function endpoint especially when measured under supervision in the clinic ${ }^{[29]}$. We assessed pulmonary artery pressure only by measuring tricuspid valve regurgitation velocity. Echocardiography was proved to be a reliable alternative to right heart catheterization in measuring pulmonary artery pressure ${ }^{[30] \text {. }}$
Financial and nonfinancial activities and relations of interest

None to be declared. The researchers did not receive any specific grant, and the research completely financed by them.

\section{REFERENCES}

1. Boulet LP. Airway remodeling in asthma: update on mechanisms and therapeutic approaches. Curr Opin Pulm Med. 2018 Jan; 24 [1]: 56-62. DOI: 10.1097/MCP. 0000000000000441.

2. Forfia PR, Vaidya A, Wiegers SE. Pulmonary heart disease: The heart-lung interaction and its impact on patient phenotypes. Pulm Circ. 2013 Jan;3[1]:5-19. DOI: 10.4103/ 2045-8932.109910.

3. Pavlicek M, Wahl A, Rutz T, de Marchi SF, Hille R, Wustmann $\mathrm{K}$, et al. Right ventricular systolic function assessment: rank of echocardiographic methods vs. cardiac magnetic resonance imaging. Eur J Echocardiogr. 2011;12[11]:87180. DOI: $10.1093 /$ ejechocard/ jer138.

4. Koestenberger M, Friedberg MK, Ravekes W, Nestaas E, Hansmann G. Non-Invasive Imaging for Congenital Heart Disease: Recent Innovations in Transthoracic Echocardiography. J Clin Exp Cardiolog. 2012 Jan 22; Suppl 8:2. DOI: 10.4172/2155-9880.S8-002.

5. Global Strategy for Asthma Management and Prevention, Global Initiative for Asthma [GINA], 2015. https://ginasthma. org/. Last accessed on April 20, 2021.

6. Campbell RM, Douglas PS, Eidem BW, Lai WW, Lopez L, Sachdeva R. ACC/AAP/AHA/ASE/HRS/SCAI/SCCT/ SCMR/ SOPE 2014 appropriate use criteria for initial transthoracic echocardiography in outpatient pediatric cardiology: a report of the American College of Cardiology Appropriate Use Criteria Task Force, American Academy of Pediatrics, American Heart Association, American Society of Echocardiography, Heart Rhythm Society, Society for Cardiovascular Angiography and Interventions, Society of Cardiovascular Computed Tomography, Society for Cardiovascular Magnetic Resonance, and Society of Pediatric Echocardiography. J Am Coll Cardiol. 2014 Nov 11; 64[19]:2039-60. DOI: 10.1016/j.jacc.2014.08.003.

7. Lai WW, Geva T, Shirali GS, Frommelt PC, Humes RA, Brook MM, Pignatelli RH, Rychik J; Task Force of the Pediatric Council of the American Society of Echocardiography; Pediatric Council of the American Society of Echocardiography. Guidelines and standards for performance of a pediatric echocardiogram: a report from the Task Force of the Pediatric Council of the American Society of Echocardiography. J Am Soc Echocardiogr. 2006 Dec;19 [12]: 1413-30. DOI: 10.1016/j.echo.2006.09.001.

8. De-Paula CR, Magalhães GS, Jentzsch NS, Botelho CF, Mota CCC, Murça TM, et al. Echocardiographic Assessment of Ventricular Function in Young Patients with Asthma. Arq Bras Cardiol. 2018 Mar;110 [3]: 231-239. DOl: 10.5935/abc. 20180052. 
9. Akyuz Ozkan E, Khosroshahi HE. Evaluation of the left and right ventricular systolic and diastolic function in asthmatic children. BMC Cardiovasc Disord. 2016 Jul 8;16[1]:145. DOI: $10.1186 /$ s12872-016-0328-X.

10. Ozdemir O, Ceylan Y, Razi CH, Ceylan O, Andiran N. Assessment of ventricular functions by tissue Doppler echocardiography in children with asthma. Pediatr Cardiol. 2013 Mar;34[3]:553-9. DOI: 10.1007/s00246-012-0493-3.

11. Shedeed SA. Right ventricular function in children with bronchial asthma: a tissue Doppler echocardiographic study. Pediatr Cardiol. 2010 Oct;31[7]:1008-15. DOI: 10.1007/ s00246-010-9753-2.

12. Zedan M, Alsawah GA, El-Assmy MM, Hasaneen B, Zedan MM, Nasef NA. Clinical asthma phenotypes: is there an impact on myocardial performance? Echocardiography. 2012 May;29 [5]: 528-34. DOI: 10.1111/j.1540-8175. 2011. 01635. $x$.

13. Abdelmohsen $G$, Mohamed $H$, Mohsen M, Abdelaziz $O$, Ahmed D, Abdelsalam M. Evaluation of cardiac function in pediatric patients with mild to moderate bronchial asthma in the era of cardiac strain imaging. Pediatr Pulmonol. 2019 Dec;54[12]:1905-1913. DOI: 10.1002/ ppul. 24485.

14. Ozde C, Dogru M, Ozde Ş, Kayapinar O, Kaya A, Korkmaz A. Subclinical right ventricular dysfunction in intermittent and persistent mildly asthmatic children on tissue Doppler echocardiography and serum NT-proBNP: Observational study. Pediatr Int. 2018 Nov; 60[11]:1024-1032. DOI: 10.1111/ped.13689.

15. Zeybek C, Yalcin Y, Erdem A, Polat TB, Aktuglu-Zeybek AC, Bayoglu V, Akdeniz C, Celebi A. Tissue Doppler echocardio-graphic assessment of cardiac function in children with bronchial asthma. Pediatr Int. 2007 Dec;49 [6]: 911-7. DOI: 10.1111/j.1442-200X.2007.02486. x.

16. Elseify MY, Alsharkawy AA, Al-Fahham MM, ElHady MM. Assessment of lateral mitral, septal and tricuspid myocardial performance indices by tissue Doppler imaging in asthmatic children. Clin Respir J. 2018 Dec;12[12]:26762682. DOI: $10.1111 /$ crj.12974.

17. Funk GC, Lang I, Schenk P, Valipour A, Hartl S, Burghuber OC. Left ventricular diastolic dysfunction in patients with COPD in the presence and absence of elevated pulmonary arterial pressure. Chest. 2008 Jun;133[6]:1354-1359. DOI: $10.1378 /$ chest.07-2685.

18. Kasner M, Westermann D, Steendijk P, Dröse S, Poller W, Schultheiss HP, Tschöpe C. Left ventricular dysfunction induced by non-severe idiopathic pulmonary arterial hypertension: a pressure-volume relationship study. Am J Respir Crit Care Med. 2012 Jul 15;186[2]:181-9. DOI: 10.1164/ rccm.201110-18600C.

19. El Wahsh RA, Ahmed MK, Yaseen RI. Evaluation of left ventricular function in patients with chronic obstructive pulmonary disease with or without pulmonary hypertension. Egyptian J Chest Dis Tuberculosis 2013; 62[4]: 575-582. DOI: 10.1016/j.ejcdt.2013. 08.004
20. Elmasry OA, Attia HM, Abdel Fattah AMN. Assessment of left ventricular diastolic function in bronchial asthma: can we rely on transmitral inflow velocity patterns? Egypt J Pediatr Allergy Immunol. 2006; 4[2]: 61-69 [2006].

21. Agha HM, Ibrahim H, El Satar IA, El Rahman NA, El Aziz DA, Salah Z, et al. Forgotten Right Ventricle in Pediatric Dilated Cardio-myopathy. Pediatr Cardiol. 2017 Apr; 38[4]:819827. DOI: 10.1007/s00246-017-1588-7.

22. Peng SM, Sun P, Zeng J, Deng XM. [Cardiac function of children with bronchial asthma]. Zhongguo Dang Dai Er Ke Za Zhi. 2006 Oct;8 [5]: 388-90. Chinese. PMID: 17052399.

23. Hirono O, Kubota I, Minamihaba O, Fatema K, Kato S, Nakamura $H$, Tomoike $H$. Left ventricular diastolic dysfunction in patients with bronchial asthma with longterm oral beta2-adrenoceptor agonists. Am Heart J. 2001;142[6]: E11. DOI: 10.1067/mhj.2001.118117.

24. Tuleta I, Eckstein N, Aurich F, Nickenig G, Schaefer C, Skowasch D, Schueler R. Reduced longitudinal cardiac strain in asthma patients. J Asthma. 2019;56[4]:350-359. DOI: 10.1080/02770903. 2018.1466311.

25. Manti S, Parisi GF, Giacchi V, Sciacca P, Tardino L, Cuppari C, Salpietro C, Chikermane A, Leonardi S. Pilot study shows right ventricular diastolic function impairment in young children with obstructive respiratory disease. Acta Paediatr. 2019 Apr;108[4]: 740-744. DOl: 10.1111/apa.14574.

26. Sobhy KE, El-Korashy RIM, Ahmed MK, Fayed FGM. Right ventricular diastolic dysfunction in asthmatic patients. Egyptian Journal of Chest Diseases and Tuberculosis 2014; 63[1]: 29-32. DOI: 10.1016/j.ejcdt.2013.09.017

27. Cetin $M$, Karaboga B, Yilmaz O, Yilmaz M, Yuksel $H$ Relation between Vascular Endothelial Markers and Right Ventricular Function in the Children with Asthma. Iran J Pediatr. 2017; 27[5]: e9363 [2017]. DOI:10.5812/ijpbs. 9363

28. Sobko EA, Solov'eva IA, Kraposhina Alu, Riazanova NG, Vtiurina SS, Salmina AB, Demko IB. [Relationship between endothelial dysfunction and mechanisms of systemic inflammation in left heart remodeling in patients with bronchial asthma]. Klin Med [Mosk]. 2014;92[11]:43-8. Russian. PMID: 25796946.

29. Halpin DMG, Meltzer EO, Pisternick-Ruf W, Moroni-Zentgraf $P$, Engel M, Zaremba-Pechmann L, Casale T, FitzGerald JM. Peak expiratory flow as an endpoint for clinical trials in asthma: a comparison with $\mathrm{FEV}_{1}$. Respir Res. $2019 \mathrm{Jul}$ 18;20[1]:159. DOI: 10.1186/s12931-019-1119-6.

30. Parasuraman S, Walker S, Loudon BL, Gollop ND, Wilson AM, Lowery C, Frenneaux MP. Assessment of pulmonary artery pressure by echocardiography-A comprehensive review. Int J Cardiol Heart Vasc. 2016 Jul 4; 12:45-51. DOI: 10.1016/j.jicha. 2016.05.011. 

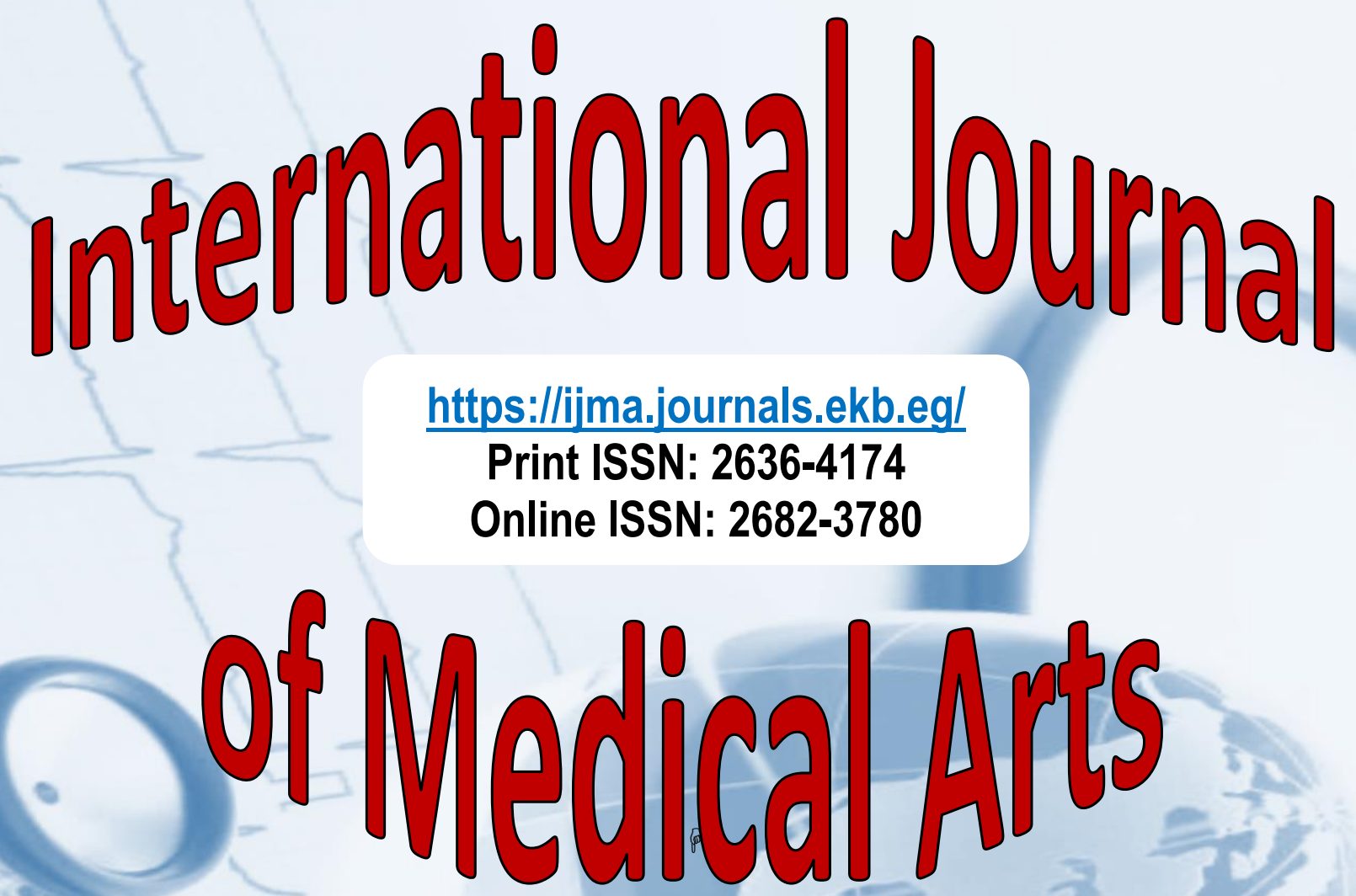